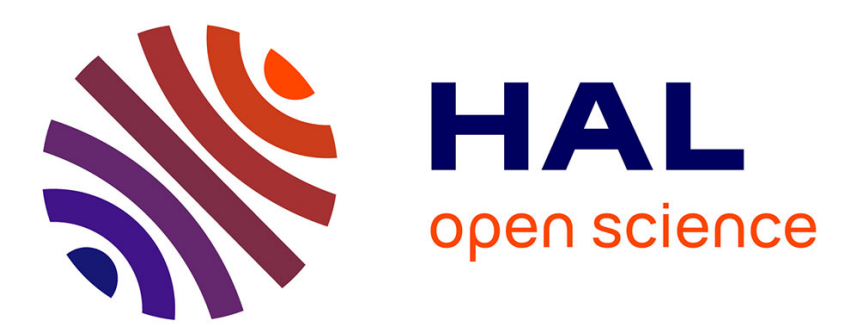

\title{
Comparative studies of excitons in magnetic asymmetric double quantum well structures
}

\author{
S. Weston, J. Nicholls, M. O’Neill, T. Stirner, P. Harrison, W. Hagston, J. \\ Hogg, B. Lunn, D. Ashenford, K. Hieke
}

\section{> To cite this version:}

S. Weston, J. Nicholls, M. O'Neill, T. Stirner, P. Harrison, et al.. Comparative studies of excitons in magnetic asymmetric double quantum well structures. Journal de Physique IV Proceedings, 1993, 03 (C5), pp.C5-401-C5-404. 10.1051/jp4:1993585 . jpa-00251672

\section{HAL Id: jpa-00251672 https://hal.science/jpa-00251672}

Submitted on 1 Jan 1993

HAL is a multi-disciplinary open access archive for the deposit and dissemination of scientific research documents, whether they are published or not. The documents may come from teaching and research institutions in France or abroad, or from public or private research centers.
L'archive ouverte pluridisciplinaire HAL, est destinée au dépôt et à la diffusion de documents scientifiques de niveau recherche, publiés ou non, émanant des établissements d'enseignement et de recherche français ou étrangers, des laboratoires publics ou privés. 


\title{
Comparative studies of excitons in magnetic asymmetric double quantum well structures
}

\author{
S.J. WESTON, J.E. NICHOLLS, M. O'NEILL, T. STIRNER, P. HARRISON, W.E. HAGSTON, \\ J.H.C. HOGG, B. LUNN* ${ }^{*}$ D.E. ASHENFORD* and K. HIEKE** \\ Department of Applied Physics, University of Hull, HU6 7RX, U.K. \\ * Department of Engineering, Design and Manufacture, University of Hull, HU6 7RX, U.K. \\ ** Humboldt-Universität zu Berlin, FB Physik, Institut für Optik und Spektroskopie, Invalidenstr. 110, \\ 1040 Berlin, Germany
}

\begin{abstract}
Four different asymmetric double quantum well structures in the dilute magnetic semiconductor system $\mathrm{Cd}_{1-x} \mathrm{Mn}_{x} \mathrm{Te}$ have been investigated. Theoretical calculations are presented which show that the observed photoluminescence (PL) and photoluminescence excitation (PLE) energies are consistent with an anticrossing of the lowest two hole states in one of the double quantum well structures when subjected to an external magnetic field.
\end{abstract}

\section{Introduction}

Asymmetric double quantum wells (a-DQWs) are ideal structures for studying electron, hole or exciton transfer between adjacent wells. In particular the study of a-DQWs of $\mathrm{CdTe} / \mathrm{Cd}_{1-x} \mathrm{Mn}_{x} \mathrm{Te}$ has the further advantage of allowing significant tuning of the band edges by application of a magnetic field. The present work describes magneto-optical results on a series of a-DQWs. All of the structures had a single CdTe well and a wider $\mathrm{Cd}_{1-y} \mathrm{Mn}_{y}$ Te well separated by a $\mathrm{Cd}_{1-x} \mathrm{Mn}_{x} \mathrm{Te}$ barrier with the concentration $x>y$. The outer barriers of the structure were of the same Mn concentration as the middle barrier. The samples were grown on (100) InSb substrates at a substrate temperature $\approx 235^{\circ} \mathrm{C}$ at a growth rate of about $1 \mu \mathrm{m} / \mathrm{hr}$. A CdTe buffer layer $1 \mu \mathrm{m}$ thick was grown before the a-DQW structure.

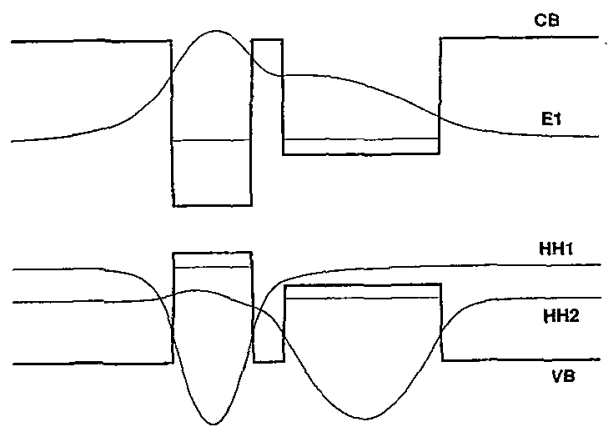

Figure 1: Band structure and wave functions corresponding to sample M413 (0T)

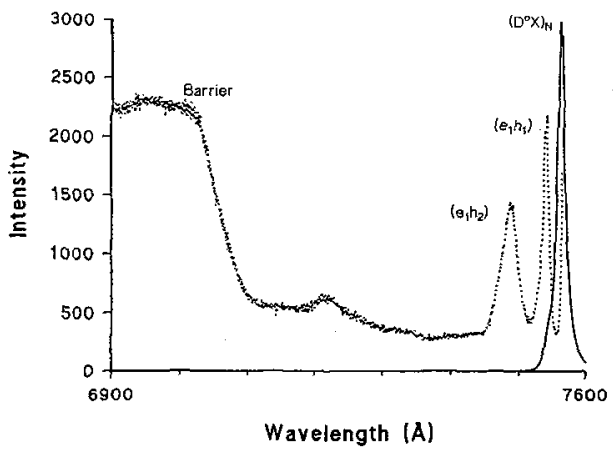

Figure 2: PL and PLE of sample M413 (0T)

The band structure (and one-particle wave functions) corresponding to sample M413 (see below) is shown in Figure 1. For this particular structure the electron wave function (E1) is delocalized over 
both wells, however, even though the central barrier is only $20 \AA$ wide, the hole wave functions (HH1 and $\mathrm{HH} 2$ ) remain essentially localized in each well. As opposed to this, in samples with wider barriers (e.g. M455 described below) the wave functions of both electron and holes are localized within each well.

\section{Experimental Results and Discussion}

Four different a-DQWs have been investigated, each with different central barrier widths. Three were grown with low $\mathrm{x}$-values, one with a higher value. Details of the structures are given in Table 1. The well widths were determined from DCXRD measurements whilst the $\mathrm{x}$-values were found from optical data relating band gap to Mn concentration [1].

Table 1: Structures of a-DQWs

\begin{tabular}{|c|c|c|c|}
\hline Sample & $\begin{array}{c}\text { Narrow well, CdTe } \\
\mathrm{L}(\AA)\end{array}$ & $\begin{array}{c}\text { Barrier } \\
\mathrm{L}(\AA), \mathrm{x}\end{array}$ & $\begin{array}{c}\text { Wide well, CdMnTe } \\
\mathrm{L}(\AA), \mathrm{y}\end{array}$ \\
\hline M413 & 50 & $20,0.107$ & $100,0.035$ \\
M458 & 50 & $50,0.075$ & $100,0.025$ \\
M445 & 50 & $200,0.057$ & $100,0.03$ \\
M455 & 40 & $60,0.23$ & $80,0.08$ \\
\hline
\end{tabular}

The PL of sample M413, shown in Figure 2, consists of two overlapping emission bands attributed to free- and donor-bound excitons respectively. It is important to note that at all values of the magnetic field only one emission band is observed, which shows that rapid relaxation between the hole states occurs on a time scale that is appreciably shorter than the exciton recombination time. The PLE spectrum, recorded at zero magnetic field whilst monitoring the $\left(D^{0} X\right)_{N}$ emission, shows the $(e 1 h 1)_{N}$ transition of the narrow well and the $(e 1 h 2)_{W}$ transition of the wide well (easily identified by its broadened line width owing to alloy fluctuations in the well) together with the outer barrier states. The behaviour of the $(e h)_{N}$ and the $(e h)_{W}$ transitions as a function of magnetic field in the Faraday configuration are shown in Figure 3. Weaker transitions which are only observed above $0.5 \mathrm{~T}$ are attributed to light hole transitions associated with the two wells. Confirmation of the heavy hole nature of the $(e h)_{N}$ and $(e h)_{W}$ transitions was provided by the reduced splitting in the Voigt configuration [2].

From Figure 3 it can be seen that the lower energy $\sigma^{+}$component of the $(e h)_{W}$ transition occurs below the $(e h)_{N}$ transition above a field of $1.4 \mathrm{~T}$. This is consistent with an anticrossing of the hole states ( $\mathrm{HH} 1$ and $\mathrm{HH} 2$, Figure 1 ) as predicted by the theoretical calculations. However, since the line widths of these transitions $(\approx 6 \mathrm{meV})$ are greater than the calculated energy difference between the hole states $(1.2 \mathrm{meV})$, the anticrossing nature of these states cannot be confirmed experimentally. As a result of this predicted anticrossing the hole state originally located in the narrow well $\left(\mathrm{H}_{N}\right)$ becomes located in the magnetic well $\left(\mathrm{H}_{W}\right)$ and vice versa, as depicted in Figure 4 . This is accompanied by a broadening of the PL line and a corresponding increase in the Stokes' shift resulting in part from 
alloy fluctuations in the magnetic well.

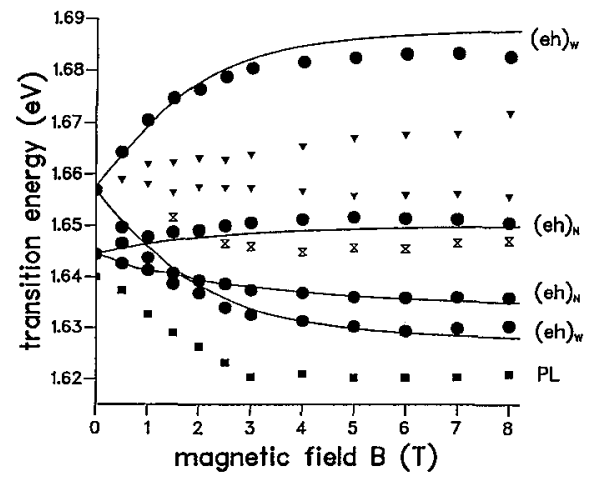

Figure 3: Transition energies of sample M413 as a function of magnetic field $B$

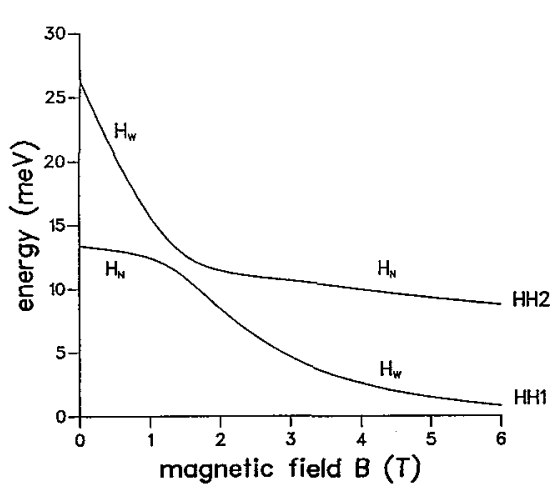

Figure 4: Energy of lowest two hole states of sample M413 as a function of magnetic field $B$

The excitonic transition energies were calculated using techniques we have previously described $[3,4]$. One interesting feature of these calculations, shown in Figure 5, concerns the variation in the exciton binding energies resulting from the anticrossing of the hole states. Using these calculated binding energies, good overall agreement between the calculated $(e h)_{N}$ and $(e h)_{W}$ transition energies and those observed experimentally is obtained for values of the valence band offset in the range 0.35 to 0.45 for the magnetic variation of the $(e h)_{N}$ and $(e h)_{W}$ states shown in Figure 3, serving to confirm, in agreement with other workers, e.g. Wasiela et al. [5], that a significant fraction of the band offset occurs in the valence band.

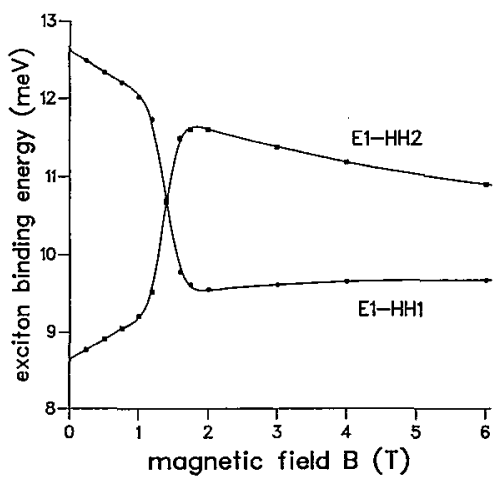

Figure 5: Exciton binding energies of sample M413 as a function of magnetic field $B$

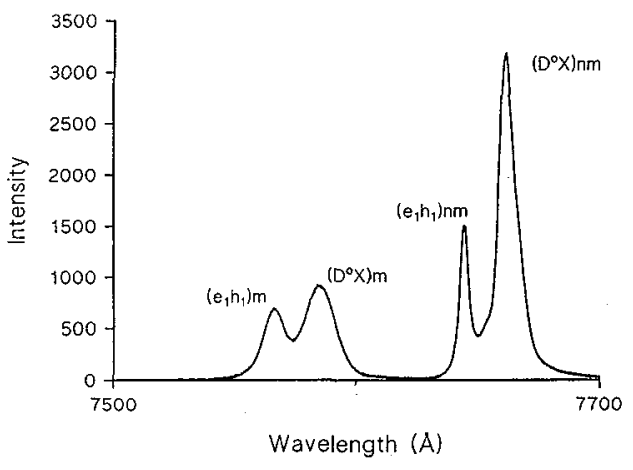

Figure 6: PL spectrum of sample M445 (0T)

Finally we mention briefly the other a-DQW samples listed in Table 1. The structure M458 is similar to that of M413, except that the central barrier is wider but lower. Again, as with M413, emission is only observed from the narrower well at zero field (indicating efficient hole transfer between the two wells). However, unlike M413, an additional weak emission from the wider well is observed in a magnetic field greater than $6 \mathrm{~T}$, consistent with a smaller energy difference in the two excitonic states in M458 compared with M413 at the higher field values. 
In samples M445 and M455 the central barrier provides more isolation between the two wells, leaving them essentially uncoupled and thus reducing the relaxation rates of electrons and holes between them. Consequently photoluminescence emission is observed from both wells as can be seen in Figure 6. Finally we note that in these structures, where the electrons and holes are localized in each well, the possibility exists of exciton emission involving recombination of an electron in one well with a hole in the adjacent well, as has recently been observed by Lawrence et al. [6]. However in our structures no clear evidence for such an indirect excitonic transition has been found.

\section{Conclusions}

Magneto-optical data on different a-DQWs are consistent with relaxation of holes between the wells, which becomes progressively reduced in samples with wider central barriers. The magnetic field at which anticrossing of the heavy hole states occurs in one of the samples with a narrow central barrier is consistent with a valence band offset of between 0.35 and 0.45 .

\section{Acknowledgements}

The authors wish to thank the Science and Engineering Research Council (U. K.) for supporting this work. One author (T. S.) would like to thank the University of Hull for the award of a Brynmor Jones Scholarship.

\section{References}

[1] Twardowski A., Nawrocki M. and Ginter J., Phys. Stat. Sol. 96 (1979) 497

[2] Peyla P., Wasiela A., Merle d'Aubigné Y., Ashenford D. E. and Lunn B., Phys. Rev. B 47 (1993) 3783

[3] Hilton C. P., Hagston W. E. and Nicholls J. E., J. Phys. A 25 (1992) 2395

[4] Hilton C. P., Goodwin J., Harrison P. and Hagston W. E., J. Phys. A 25 (1992) 5365

[5] Wasiela A., Peyla P., Merle d'Aubigné Y., Nicholls J. E., Ashenford D. E. and Lunn B., Semicond. Sci. and Technol. 7 (1992) 571

[6] Lawrence I., Feuillet G., Tuffigo H., Bodin C., Cibert J., Peyla P. and Wasiela A., Superlatt. and Microstruct. 12 (1992) 119 